Cite as: Sheaves M, Johnston R, Connolly RM (2012) Fish assemblages as indicators of estuary ecosystem health. Wetland Ecology and Management 20:477-490

\title{
Fish Assemblages as Indicators of Estuary Ecosystem Health
}

\section{Marcus Sheaves, Ross Johnston and Rod M. Connolly}

Marcus Sheaves \& Ross Johnston: Estuary and Tidal Wetland Ecosystems Research Group, School of Marine and Tropical Biology, James Cook University, Townsville, Queensland 4811, Australia

Rod M Connolly: Australian Rivers Institute - Coast and Estuaries, and School of Environment, Griffith University, Gold Coast, Queensland 4222, Australia

\begin{abstract}
Understanding and managing increasing threat from diverse anthropogenic pressures on estuaries requires impact assessment and monitoring indices that provide accurate quantification of change and are readily communicable. Although indices based on nekton assemblage structure have obvious appeal to managers, the imperative to produce the most accurate measures possible has seen a move away from simple composite measures (such as diversity indices) towards complex multivariate approaches. However, complex methods often provide a poor basis for reporting because they can be difficult to report in terms that are meaningful to the end user. Effective indices should be simple to construct and communicate, relate directly to definable biological attributes, fall within predictable ranges for unimpacted systems and show demonstrable responses to known impacts. We use published nekton data for 30 natural and 2 artificial estuaries to develop a set of nekton assemblage-based summary measures that fit these criteria. We evaluated a suite of simple parallel measures based on both catch per unit effort (CPUE) and probability of encounter (PoE). Parallel measures provide complementary information thus a more robust assessments of change. Three measures fell within consistent bounds as long as comparisons were confined to the same time of year to remove the influence of seasonal variability, and were efficient at differentiating degraded from unimpacted estuaries. Because the successful approaches rely on PoE rather than CPUE they have considerable tactical advantages in that they are less destructive, allow for the collection of many more samples per unit time, and treat schooling and non-schooling species equivalently.
\end{abstract}

Key words: monitoring; assessment; environmental change; CPUE; probability of encounter; diversity indices 


\section{Introduction}

Estuaries occur at the confluence of land and sea, and form a natural link between terrestrial and aquatic freshwater habitats and the marine environment. Consequently, they mediate transfers between the terrestrial environment and the ocean, with their position at the terminus of rivers making them not only conduits for the transfer of potential environmental stressors (e.g. pollutants or floodwaters) but sites that are likely to be exposed to high levels of stressors (Kennish, 2002). Moreover, the attractiveness of estuaries and their surrounding areas as sites for diverse human activities means they exist in areas where the generation of stressors is particularly high. As a result, estuaries are under increasing threat from a wide range of natural and anthropogenic pressures, leading to an increasing emphasis on impact assessment and monitoring (eg. Noble and Storey, 2004; Smith et al., 2007; Elliott and Quintino, 2007) that makes accurate quantification of change an urgent imperative (Elliott, 2002).

In recent years there has been a move towards multi-metric indices of ecosystem health (Bain et al., 2000; Love and May, 2007; Borja et al., 2008), usually incorporating measurements of the state of the physico-chemical environment, habitat condition, and animal and plant components (e.g. Clapcott et al., 2012). Within this, there has been a shift in focus away from species-specific to multi-species measures because of recognition of the utility of such approaches by both science and management (Simon, 2000). Composite assemblage-focussed indices (e.g. diversity indices) have a long history of application to monitoring and assessment but have recently fallen from favour because of the loss of detail in producing such condensed summaries (Kennard et al., 2006) and because of perceived poor performance (Maddock, 1999). However, although potentially more informative, more complex assemblage measures, such as multivariate statistical approaches, are complex and difficult to interpret. This produces problems of its own because paralleling the need for quantification of impacts is the requirement for effective, end-user focussed reporting (Cooper et al., 1994 ). This is particularly the case with the current move towards simple, informative communication products, such as fact sheets and report cards that provide userfriendly summaries of ecological condition (Whitfield and Elliott, 2002; Dennison et al., 2007), and the increasing involvement of community groups in monitoring and assessment (Graham et al., 2004). Although many successful monitoring and assessment approaches exist for fish (e.g. Harrison and Whitfield, 2004) many others include qualitative measures for non-fish data that are not available for tropical systems in developing countries where estuaries are numerous but are data poor. Similarly studying ecosystem health by examining health of individual organisms can be successful but this is often costly and can demand a high degree of technical expertise (Schlacher et al., 2007). The mismatch between the need for simple, directly interpretable measures that are easy to initiate, analyse and communicate, and the need for detailed description has no single solution but does suggest that efforts to produce simple indices that provide relevant information, need to continue. Such indices should be easy to interpret and follow a simple adoption pathway that is amenable to science, management and community organisations.

Not only do indicators need to be meaningful, but they must take a form that end-users can relate to (Cooper et al., 1994). Fish assemblages are often seen as ideal targets for monitoring and reporting (Ward et al., 1998) because fish are relatively large, easy to identify, taxonomically well understood and familiar to the public through their use as food and as targets for recreational fishing (Harrison and Whitfield, 2004). Despite their attractiveness, indices based on fish assemblages are not widely used in monitoring and reporting. For instance, Western Australia’s report card for the Australian National Land and Water 
Resources Audit is principally based on expert opinion rather than biological data (Forbes et al., 2008), and even the well developed monitoring and reporting in the Ecosystem Health Monitoring Program in South East Queensland (EHMP, 2008), the mini SASS approach for monitoring South African rivers (Graham et al., 2004) and many biological indices developed in the USA (e.g. Ode et al., 2005) include no fish-based indices. Even where estuarine fish assemblages have been included in reporting they have often proved to be poor at differentiating estuaries with different apparent levels of ecosystem condition (Moore et al., 2007). This lack of differentiation may be a reflection of the "estuarine quality paradox" which suggests that estuarine fish assemblages are adapted to a physically demanding environment where natural and anthropogenic stressors have similar features making segregation of effects difficult (Elliott and Quintino, 2007). Despite this fish have proved useful for monitoring (Whitfield and Elliott, 2002) and remain viable targets for development of simple reporting approaches.

Recently a number of large-scale studies (e.g. Ley, 2005; Sheaves, 2006) have shed light on the spatio-temporal variability in Australia's dry tropics fish fauna. However, this improved understanding has highlighted the difficulties of using fish assemblages as tools for monitoring and evaluation. Studies of 9 estuaries spanning $180 \mathrm{~km}$ (Sheaves, 2006) and 21 estuaries spanning $650 \mathrm{~km}$ (Sheaves and Johnston, 2009) of the coastline of tropical northern Australia show assemblages of adjacent estuaries are likely to be no more similar than those of estuaries 100s of kilometres apart. There was also no simple monotonic relationship between measures such as species richness or catch per unit effort (CPUE), and impact status (Sheaves and Johnston, 2009). As a result, there is no simple way of determining what a "normal” assemblage should look like, given our current level of understanding.

Consequently, it is difficult to compare assemblages among estuaries, to determine if one estuary is more impacted than another, to define control sites, or define absolute standards of estuarine condition or health based on fish assemblage structure. However, the presence of unique fish assemblages that remain distinct among seasons (Ley and Halliday, 2003) and years (Sheaves, 2006) indicates temporal consistency within individual estuaries suggesting that fish assemblage structure can provide a useful measure of estuary condition or health, as long as a dynamic, sites-specific view is taken; an approach that accords particularly well with the logic of monitoring. In particular indices based on how likely it is to encounter a particular species (probability of encounter [PoE]), rather than CPUE, show considerable promise (Sheaves and Johnston, 2010).

Although the PoE indices developed by Sheaves and Johnston (2010) have many operational benefits, and performed well in comparisons with multivariate analyses, they need to be developed to a stage where they can be used as components of integrated indicator packages. In this context, simple summary measures of community structure, such as measures of diversity and indices of overall abundance, have distinct advantages because of the ease with which they can be translated into communication products such as report cards. Additionally, notwithstanding the difficulties with defining 'normal' assemblage structure, there is still an obvious need to provide guidelines for developing useful initial baselines. Such indices should relate directly to definable biological attributes, fall within predictable ranges for unimpacted systems, and show demonstrable responses to known impacts. Moreover, indices should be simple to construct and communicate to facilitate application and interpretation by community and management organisations rather than require higher level statistical skills to extract information. Here we use published nekton data for a suite of well studied tropical estuaries to develop a set of simple nekton assemblage-based summary measures that fit these criteria and have the potential to form part of an integrated indicator package. 


\section{Methods}

We used 3 pre-existing data sets (studies 1,2,3), collected across a range of estuaries in tropical north Queensland, Australia (Fig. 1), as a basis to develop a simple set of nekton assemblage-based summary measures that could be used to assess and monitor estuarine health. The first two data sets employed cast net sampling with only minor differences in methods. Study 1 investigated nekton distributions across 21 estuaries spanning $650 \mathrm{~km}$ of coastline (Sheaves and Johnston, 2009) with sampling focussed on a single common habitat, low-angle banks (Johnston and Sheaves, 2007) that held highest probability of encountering small fish (Johnston and Sheaves, 2008). Study 2 focussed on 11 estuaries along $225 \mathrm{~km}$ of coastline over 15 months (Sheaves et al., 2010). In this case sampling aimed to represent all available habitats rather than concentrating on the most common habitat, potentially producing slightly lower catch rates and slightly more species; however initial evaluation showed no clear pattern of difference that could be attributed to the differences in sampling methods. Study 3 is based on seine net sampling of 9 estuaries spanning $200 \mathrm{~km}$ of coastline over 3 years (Sheaves, 2006).

Although Australia has a national estuary data base (http://www.ozcoasts.org.au/) it does not provide sufficient detail for northern Australia to allow comparison of potential impact levels among specific estuaries. To overcome this we used a modified Delphi approach (Linstone and Turoff, 2002), based on published information, the combined experience of research workers familiar with north Queensland estuaries and extensive ground truthing, to construct a 'naturalness' categorisation for the 32 estuaries in Studies 1 and 2. To account for any differences that estuary size may have on the possible effects for any given impact, e.g. greater dilution effects in larger volume systems, the extent of potential impact was considered relative to the approximate volume of each estuary. Initial Delphi-based consideration of the quality of available information indicated 8 variables could be reliably assessed: (1) the integrity of life-history connectivity with adjacent ecosystems, (2) the extent of estuary habitat modification, (3) the intactness of tidal wetland habitats, (4) the intactness of seasonal wetland habitats, (5) the potential for agricultural pollution, (6) the potential for urban pollution, (7) the potential for anthropogenically altered sediment loads, and (8) the amount of boat traffic. Each of these potential impacts was ranked on a scale of 0-10, and the ranks combined to provide an overall ranking of 'naturalness'. Although it would be preferable to apply different weights to the different 'impact variables' relative to their importance there was no basis on which to define such weightings. However, differences in variance among the measures were accounted for by using PCA to rank sites, rather than using unweighted rank sums. Rankings of sites along first Principal Component (that explained $57 \%$ of variation in the naturalness data) showed high correlation with the simple rank sums ( $\mathrm{r}=0.97$, largest difference in ranks 3 (out of 32 estuaries)). The final rankings were reviewed by the expert panel. Relationships between 'naturalness' and 3 simple nekton summary measures; mean CPUE over species, mean PoE over species and mean species richness (S) were investigated. Mean PoE was calculated as the mean number of nets in which a species was present for each sampling unit (10 nets). Because of differences in the number of cast nets among estuaries species richness was standardised to 40 nets using species accumulation curves.

The relationship between CPUE and PoE was investigated for the 3 most common nekton over Studies 1 and 2; the penaeid, Penaeus merguiensis, juveniles of the offshore spawning leiognathid, Leiognathus equulus, and the estuary resident ambassid, Ambassis vachelli. The 
relationships were modelled using linear regression following power (log-log) transformations. A number of simple nekton assemblage-based indices were calculated for the 3 data sets to allow their utility as measures of estuary health to be evaluated. Bivariate scatterplots of species richness (S) versus Pielou's evenness (J), the two components of Shannon diversity (H) (Legendre and Legendre 2003), with isopleths of H constructed to allow comparison of the usefulness of these different aspects of diversity. Additionally, both $\mathrm{J}$ based on CPUE ( $\left.\mathrm{J}_{\mathrm{CPUE}}\right)$, and $\mathrm{J}$ based on PoE $\left(\mathrm{J}_{\mathrm{PoE}}\right)$ were investigated, as were both mean CPUE and mean PoE (both calculated as means across all species for an estuary).

\section{Results}

Despite a broad range of impact levels, there was no clear relationship between naturalness and summary ecological measures for the 30 natural estuaries investigated (Fig. 2). The natural estuaries spanned the full range of impact scenarios found in tropical Australia, from Ross River (flowing through a major city and having freshwater inflow modified by 3 weirs and a dam), Packer Creek (the site of a major tourist development with extensive channel modification, boat moorings, marinas a large town downstream, and sugar cane plantations upstream) and Mossman River (surrounded by sugar cane plantations, with freshwater inflow passing through the major urban centre in the area) to the almost pristine Deluge, Armstrong and Waterfall Creeks, where the only obvious impact is light recreational angling pressure ( $<5$ boats per day). Notwithstanding this there was neither any indication of increase in mean CPUE, mean PoE or species richness as naturalness increased nor a humped relationship between naturalness and the summary measures as might be expected under an intermediate disturbance scenario.

All the summary measures reflected the highly impacted natures of the two artificial estuarine lakes (Fig. 2), with very low species richness and highly variable mean CPUE and mean PoE. Highly variable mean CPUEs resulted from extremely large catches of a single species, the planktivore Herklotsichthys castelnaui, but low catches of all other species. Parallel highly variable mean PoEs had a related cause with $H$. castelnaui occurring in almost half the nets (i.e. high PoE) while all other species were captured in 3 or fewer nets. Highly variable mean CPUE, but not mean PoE, for Waterfall Creek, the most 'natural' estuary, illustrates a disadvantage of CPUE compared to PoE. The highly variable mean CPUE was due to a single large catch (1222) of Ambassis vachelli. Because mean PoE was not influenced by the size of this catch its value and variability are consistent with those for other natural estuaries, which is in keeping with high number of species at Waterfall Creek.

Strong linear relationships between log PoE and log CPUE (Fig. 3) indicate that, despite different specific interpretations (CPUE: how many; versus PoE: how likely to encounter), they are essentially estimating the same thing, at least in regards to estuary health; high PoE can be taken to imply underlying high CPUE (i.e if extreme catches are ignored) and, given the problems caused by extreme samples, may be a more reliable index of overall abundance than CPUE.

Diversity measures, such as Shannon-Weaver $\mathrm{H}$, that combine species richness (S) and equitability (J), do not reflect assemblage change effectively. Simple plots of J v S with isopleths of $\mathrm{H}$ (Fig. 4) demonstrate the problem; clear differences are evident in plots of $\mathrm{J}$ v S however when $\mathrm{H}$ is used in isolation a variety of combinations of $\mathrm{S}$ and $\mathrm{J}$ lead to the same $\mathrm{H}$ outcome. For instance, $\mathrm{H}$ values for the unimpacted Doughboy Creek were between 1 and 1.5 for November 2007, December 2007, and March 2008 despite substantial differences in 
species richness (36, 44, and 25 species respectively). Values of $\mathrm{H}$ were also approximately between 1 and 1.5 for the heavily impacted Curralea Lake for March 2008 (5 species) and November 2008 (12 species), and Keyatta Lake for May 2008 (13 species). In essence, $\mathrm{H}$ had little utility in detecting spatio-temporal changes in either the number of species or the equitability in which numbers of individuals were distributed among species, of magnitudes that would probably be of concern. One obvious way around this problem is to use both $S$ and $\mathrm{J}$ or joint plots of S versus $\mathrm{J}$ to evaluate assemblage change.

The timing of sampling is critical for producing reliable indicators. Whatever measures of assemblage change are used it is critical that their collection and comparison is sensitive to seasonal variation. For instance, for each of the 7 estuaries from Study 2 with the most temporally extensive data, $\mathrm{S}$ varies between seasons but is fairly consistent among months within a season, particularly for the low recruitment post-wet and dry seasons (Fig. 5). The pre-wet season instability is highlighted by greater variation in S between pre-wet season months (November, December) in 2008 than 2007, reflecting delayed recruitment in 2007.

Traditional approaches to calculating equitability may not provide the most reliable indices of change. For the Study 2 estuaries, J calculated from CPUE $\left(\mathrm{J}_{\mathrm{CPUE}}\right)$ is much more variable between succeeding post-wet season months (a stable time of year) than $\mathrm{J}$ calculated from probability of encounter $\left(\mathrm{J}_{\mathrm{PoE}}\right)$ (Fig. 6). Parallel to the situation for mean CPUE compared to mean PoE (Fig. 2), large differences in $\mathrm{J}_{\mathrm{CPUE}}$ between months in an individual estuary mainly resulted from one or two large catches of a single species; essentially, $\mathrm{J}_{\mathrm{CPUE}}$ is sensitive to sampling error in terms of the actual size of catches whereas $\mathrm{J}_{\mathrm{PoE}}$ is more stable because it is only based on number of nets in which each species was present.

While $\mathrm{S}$ and $\mathrm{J}_{\mathrm{PoE}}$ seem likely to provide simple, broad summaries of assemblage change they do not address changes in overall abundance. The inclusion of mean PoE into the indicator mix seems useful. Mean PoEs for natural Study 2 estuaries showed low variability at any one month (Fig. 7), although clear patterns of temporal change mean PoE is sensitive to changes in relative abundance. In contrast, PoEs of impacted sites were low and often very variable, suggesting low and/or variable mean PoEs are likely to be characteristic of impacted systems.

Two examples illustrate the potential usefulness of a combined indicator suite comprising $S$, mean PoE and $\mathrm{J}_{\mathrm{PoE}}$. Mean PoEs, $\mathrm{S}$ and $\mathrm{J}_{\mathrm{PoE}}$ all showed show considerable year-to-year stability for individual estuaries of study 3 (Fig. 8), indicating that each of the measures is likely to remain stable for a site if impact conditions don't change. Mean PoE and $J_{P o E}$ values for all these unimpacted estuaries fall within relatively discreet bands well separated from zero, indicating a range of values that could be used as preliminary indications of expectations for other sites within the region. Values of S are more variable and not so well separated from zero, indicating that, by itself, it would not provide reliable indication of impact until species numbers reached a very low level. The Study 2 data for two months (one post-wet and one dry season) show the types of combined mean PoE $/ \mathrm{S} / \mathrm{J}_{\mathrm{PoE}}$ signatures that would indicate degraded sites (Fig. 9). In April 2008 the impacted "Lakes" sites showed low mean PoE, low $\mathrm{S}$ and high $\mathrm{J}_{\mathrm{PoE}}$ compared to 9 natural estuaries. The high $\mathrm{J}_{\mathrm{PoE}}$ values resulted from the capture of a few species in a very few nets each, leading to very similar PoEs for all species and hence unusually high $\mathrm{J}_{\mathrm{PoE}} \mathrm{S}$. The signature of degradation is a little different for the July 2008 samples. Again S is low for the "Lakes" sites but mean PoEs for the "Lakes" are not unusually low against the background seasonally low PoEs of the natural estuaries. However, Keyatta Lake did have the lowest mean PoE, that, as for the April 2008 sample matched with an unusually high $\mathrm{J}_{\mathrm{PoE}}$, while Curralea Lake featured a very variable mean PoE (1 species occurring in many nets) that matched with very low $\mathrm{J}_{\mathrm{PoE}}$. Overall, when viewed 
together the combination of the 3 simple measures appears to provide a good indication of estuary health.

\section{Discussion}

Although simple indices of estuarine health based on measures of faunal diversity or abundance are attractive, they have consistently performed poorly in assessment or monitoring (Moore et al., 2007). However, it is likely that the problem is not necessarily in the indices themselves but the way they are interpreted. Two problems have hampered the development of simple nekton-based indices of tropical estuarine health. In many cases indicator development appears to have been based on an implicit assumption that there should be a simple relationship between simple summary ecological measures and 'naturalness' or the level of degradation (e.g. Graham et al., 2004; Ode et al., 2005). This was clearly not the case for the 30 natural estuaries from study one and study two data, which showed neither an increase of any of the measures with 'naturalness' nor the humped distribution expected under an intermediate disturbance scenario. This problem is exacerbated by estuary-to-estuary faunal variation (Ley, 2005; Sheaves and Johnston, 2009) that means adjacent estuaries often look no more alike than estuaries hundreds of kilometres away, meaning there can be no expectation that current condition of an estuary can be reliably referenced to a nearby control site. These two characteristics of tropical estuarine nekton assemblages mean that any attempt to judge estuary condition relative to a theoretical absolute standard is doomed to failure, no matter what index is employed. Consequently, the first step to developing effective nekton-based indices is to step away from the idea that assemblage structure can be judged relative to an absolute standard. Rather, these considerations mean that assemblage structure can only be effectively evaluated relative to a historical sequence of assemblage structures at that site. Once the focus switches from comparing assemblages to an absolute standard, to evaluating assemblage change at a site, traditional summaries of faunal structure become much more viable indices.

The suite of three indices developed here (mean CPUE over species, mean PoE over species and mean species richness (S)) match with the criteria of (1) being simple to construct and communicate, (2) relating directly to definable biological attributes, (3) falling within predictable ranges for unimpacted systems, and (4) showing demonstrable responses to known impacts. PoE approaches can be used effectively as stand-alone indices without compromising assessments of estuarine health unduly. This may be a preferable approach when reporting to interest groups that don't possess the skills necessary to easily interpret the full suite of indices. The three indices are either basic summaries of key aspects of species diversity (species richness (S), evenness (JPoE)) or broad summaries of commonness of occurrence (mean PoE), making them simple to construct and meaning they relate to straightforward and complimentary biological attributes (species richness; how many species there are, $\mathrm{J}_{\mathrm{PoE}}$; how the numbers are distributed among species, and mean PoE; how common nekton are overall). Despite estuary-to-estuary variation all three measures fell within consistent bounds whether collected with seine nets or with cast nets, and these bounds were consistent as long as samples were collected at the same time of year. The ability of the indices to detect environmental degradation is more contentious. Estuaries such as Ross River, Packer Creek and Mossman River are obviously influenced by substantial urban, tourist or agricultural development (Sheaves and Johnston, 2009) but show no obvious responses for any of the indices. It seems that, despite the obvious potential for adverse impacts, fish faunal structure is relatively unaltered in these estuaries. This highlights the 
obvious point that any measure of health is only sensitive to those impacts that affect the target organisms. In these cases more appropriate measures of ecosystem health would be the extent of habitat alteration or loss, or levels of chemical accumulation in animal tissues. In contrast, the indices were efficient at detecting impacts that directly altered faunal composition, with consistently anomalous values for the artificial estuarine Keyatta and Curralea Lakes; both sites with histories of fish kills (Sheaves and Johnston, 2010).

Basing indices on PoE rather than CPUE has real benefits. Unusually large catches of schooling species in a single replicate led to highly variable mean CPUE for one of the most pristine estuaries; in effect sampling variability made a pristine site appear more similar to the highly impacted "Lakes" than to other natural estuaries. In contrast, mean PoE is unaffected by such anomalous catches leading to more consistent and repeatable representation (Legendre and Legendre, 2003; Sheaves and Johnston, 2009). For the same reason $\mathrm{J}_{\mathrm{PoE}}$ is more stable than $\mathrm{J}_{\text {CPUE }}$. PoE also has the effect of allowing more species to contribute to indices. CPUE-based indices emphasise species with the highest catches, often schooling species. Species that occur regularly but in low numbers usually contribute little to CPUE indices. PoE treats both types of species equivalently, enabling low abundance species that occur regularly (i.e. that are indicative of a site and occur most reliably) to contribute equally to assessments (Manley et al., 2004). PoE is also attractive on conservation grounds because it is usually possible to release almost all captured fish (Schorr et al., 1995; Sheaves and Johnston, 2008) since data collection only requires identification of the species that are present. Additionally, in-field identification means that much more data can be collected per unit field time (Gayraud et al., 2003; Badenhausser et al., 2007) because there is no need for the time consuming tasks of euthanizing, package and laboratory processing. Beyond these considerations the question addressed by PoE, of how likely it is to encounter a particular species, may actually be more relevant to many assessments than questions of how many animals can be caught that are addressed using CPUE. Such considerations as those presented above have led to PoE being used successfully in distributional studies of terrestrial vertebrates (Manley et al., 2004; Msoffe et al., 2007), insects (Reece and McIntyre, 2009) and zooplankton (Omundsen et al., 2000), conservation (Steinitz et al., 2005) and monitoring assessment (Gayraud et al., 2003) and for less obvious applications such as descriptions of fish diets (Baker and Sheaves, 2005).

Although the lack of absolute standards for faunal composition means that base-lines need to be established based on the assemblages at the particular sites of interest, there is the obvious need for "working base-lines" to allow initial provisional assessment (Newall et al., 2006; Sheaves and Johnston, 2010). The relatively consistent values of mean PoE, S and $\mathrm{J}_{\mathrm{PoE}}$ across the natural estuaries suggests that with a large enough base of sample estuaries from a region defining "provisional” base-lines is possible. However, in comparing to provisional baselines it is critical to carefully consider goals and expectations. Base-lines need to be tight enough so that indices would reliably provide early warning of situations where faunal composition was degraded. The corollary of this is that the indices should be expected to show some false positives; unimpacted estuaries that have naturally have low numbers of species or low abundances. This should not be seen as a failure of the indices or the baselines but an indication of the sites that require more detailed investigation to determine why index values are anomalous. It is also important that provisional baselines are continually reevaluated in the light of the ever increasing body of data accumulating for study estuaries as a result of monitoring.

No matter how potentially useful an indicator suite might be its value is ultimately determined by the quality of data on which it is based (Seegert, 2000). This means that 
careful sampling design and implementation is critical (Cooper et al. 1994; Badenhausser et al., 2007). Seasonal variation in faunal composition means that the timing of sampling is critical. For tropical Australian estuaries faunal composition is consistent for low recruitment seasons so samples should be collected during the post-wet and dry seasons and sampling avoided during the late pre-wet and wet seasons. Variability in index values could be minimised by stratifying by habitat type. Here the interaction with the sampling gear used is important. Gears need to be appropriate for the dominant habitat(s) available at an estuary, so they collect nekton efficiently to produce stable, repeatable data and represent the fauna of the estuary as completely as possible. Gears that can be used to collect larger numbers of replicate samples per unit time and that can be used across a variety of sites will usually be preferable, to allow faunal representation to be as spatially extensive as possible and to allow PoEs to be based on as many replicates as possible. Consistency of sampling is also important. So, while the measures described here are simple enough for community monitoring, quality outcomes require extensive operator capacity building and continual quality control (Seegert, 2000).

\section{Acknowledgments}

This work was funded by the Marine and Tropical Sciences Research Facility as part of Project 3.7.1 Marine and Estuarine Indicators and Thresholds of Concern. We thank A. Johnson and the many volunteers whose assistance made the extensive fieldwork possible. This work was conducted in accordance with institutional, national and international guidelines concerning the use of animals in research under ethics permit A1210.

\section{References}

Badenhausser I, Amouroux P, Bretagnolle V (2007) Estimating Acridid Densities in Grassland Habitats: A Comparison Between Presence-Absence and Abundance Sampling Designs. Environmental Entomology 36,1494-1503.

Bain MB, Harigb AL, Loucksc DP, Goforthd RR, Mills KE (2000) Aquatic ecosystem protection and restoration: advances in methods for assessment and evaluation. Environmental Science and Policy 3,S89-98.

Baker R, Sheaves M (2005) Redefining the piscivore assemblage of shallow estuarine nursery habitats. Marine Ecology Progress Series 291,197-213.

Borja A, Bricker SB, Dauer DM, Demetriades NT, Ferreira JG, Forbes AT, Hutchings P, Jia X, Kenchington R, Marques JC, Zhu C (2008) Overview of integrative tools and methods in assessing ecological integrity in estuarine and coastal systems worldwide. Marine Pollution Bulletin 56,1519-1537.

Clapcott JE, Collier KJ, Death RG, Goodwin EO, Harding JS, Kelly D, Leathwick JR, Young RG (2012) Quantifying relationships between land-use gradients and structural and functional indicators of stream ecological integrity. Freshwater Biology 57,74-90.

Cooper JAG, Ramm AEL, Harrison TD (1994) The estuarine health index, A new approach to scientific information transfer. Ocean and Coastal Management 25,103-141.

Dennison WC, Lookingbill TR, Carruthers TJB, Hawkey JM, Carter SL (2007). An eyeopening approach to developing and communicating integrated environmental assessments. Frontiers in Ecology and the Environment 5, 307-314. 
EHMP (2008) Estuarine/Marine Methods and Indicators. In: Ecosystem Health Monitoring Program, Annual Technical Report 2006-07. South East Queensland healthy waterways partnership, Brisbane (pp. 30-37).

Elliott M (2002) The role of the DPSIR approach and conceptual models in marine environmental management: an example for offshore wind power. Marine Pollution Bulletin 44(6),iii-vii.

Elliott M, Quintino V (2007) The estuarine quality paradox, environmental homeostasis and the difficulty of detecting anthropogenic stress in naturally stressed areas. Marine Pollution Bulletin 54:640-645.

Forbes V, Robb M, Thomson C (2008) Development of estuarine report cards consistent with the national estuarine environmental condition assessment framework. Department of Water (Government of Western Australia), Perth.

Gayraud S, Statzner B, Bady P, Haybachp A, Schoell F, Usseglio-Polatera P, Bacchi M (2003) Invertebrate traits for the biomonitoring of large European rivers: an initial assessment of alternative metrics. Freshwater Biology 48,2045-2064.

Graham PM, Dickens CWS, Taylor RJ (2004) MiniSASS: a novel technique for community participation in river health monitoring and management. African Journal of Aquatic Science 29,25-35.

Harrison TD, Whitfield AK (2004) A multi-metric fish index to assess the environmental condition of estuaries. Journal of Fish Biology 65,683-710.

Johnston R, Sheaves M (2007) Small fish and crustaceans demonstrate a preference for particular small-scale habitats when mangrove forests are not accessible. Journal of Experimental Marine Biology and Ecology 353,164-179.

Johnston R, Sheaves M (2008) Cross-channel distribution of small fish in tropical and subtropical coastal wetlands depends on their trophic and taxonomic identities and on wetland depth. Marine Ecology Progress Series 357,255-270.

Kennard MJ, Harch BD, Pusey BJ, Arthington AH (2006) Accurately defining the reference condition for summary biotic metrics: A comparison of four approaches. Hydrobiologia 572,151-170.

Kennish MJ (2002) Environmental threats and environmental future of estuaries. Environmental Conservation 29,78-107.

Legendre P, Legendre L (2003) Numerical Ecology Elsevier Science, Amsterdam.

Ley J, Halliday I (2003) Role of fishing closures and habitat in conserving regional estuarine biodiversity: a case study in Northern Queensland, Australia. World Congress on Aquatic Protected Areas, Cairns.

Ley JA (2005) Linking fish assemblages and attributes of mangrove estuaries in tropical Australia: criteria for regional marine reserves. Marine Ecology Progress Series 305,41-57.

Linstone HA, Turoff M (2002) The Delphi Method: Techniques and Applications. http://is.njit.edu/pubs/delphibook/ accessed 22/02/11

Love JW, May EB (2007) Relationships Between Fish Assemblage Structure and Selected Environmental Factors in Maryland's Coastal Bays. Northeastern Naturalist 14,251268.

Maddock I (1999) The importance of physical habitat assessment for evaluating river health. Freshwater Biology 41,373-391.

Manley PN, Zielinski WJ, Schlesinger MD, Mori SR (2004) Evaluation of a multiple-species approach to monitoring species at the ecoregional scale. Ecological Applications 14,296-310.

Moore M, Power T, Marsden T (2007) Fish Community Condition of the Mackay Whitsunday Region, Brisbane. 
Msoffe F, Mturi FA, Galanti V, Tosi W, Wauters LA, Tosi G (2007) Comparing data of different survey methods for sustainable wildlife management in hunting areas: the case of Tarangire-Manyara ecosystem, northern Tanzania. European Journal of Wildlife Research 53,112-124.

Newall P, Bate N, Metzeling L (2006) A comparison of diatom and macroinvertebrate classification of sites in the Kiewa River system, Australia. Hydrobiologia 572,131149.

Noble B, Storey K (2004) Towards increasing the utility of follow-up in Canadian EIA. Environmental Impact Assessment Review 25,163-180.

Ode PR, Rehn AC, May JT (2005) Quantitative Tool for Assessing the Integrity of Southern Coastal California Streams. Environmental Management 35,493-504.

Omundsen SL, Sheaves MJ, Molony BW (2000) Temporal population dynamics of the swarming shrimp, Acetes sibogae australis, in a tropical near-shore system. Marine and Freshwater Research 51,249-254.

Reece BA, McIntyre NE (2009) Community assemblage patterns of odonates inhabiting a wetland complex influenced by anthropogenic disturbance. Insect Conservation and Diversity 2,73-80.

Schlacher TA, Mondon JA, Connolly RM (2007) Estuarine fish health assessment: Evidence of wastewater impacts based on nitrogen isotopes and histopathology. Marine Pollution Bulletin 54,1762-1776.

Schorr MS, Meador MR, Hill LG (1995) Incidental catch of sport fish in cast nets used to collect baitfish in Lake Texoma, Oklahoma-Texas. North American Journal of Fisheries Management 15,142-147.

Seegert G (2000) The development, use, and misuse of biocriteria with an emphasis on the index of biotic integrity. Environmental Science and Policy 3,51-58.

Sheaves MJ (2006) Scale dependent variation in composition of fish fauna among tropical estuarine sandy embayments. Marine Ecology Progress Series 310,173-184.

Sheaves, M., Johnston, R., (2008). Influence of marine and freshwater connectivity on the dynamics of subtropical estuarine wetland fish metapopulations. Marine Ecology Progress Series 357, 225-243.

Sheaves M, Johnston R (2009) Ecological drivers of spatial variability among fish fauna of 21 tropical Australian estuaries. Marine Ecology Progress Series 385,245-260.

Sheaves M, Johnston R (2010) Implications of Spatial Variability of Fish Assemblages for Monitoring of Australia's Tropical Estuaries. Aquatic Conservation Marine and Freshwater Systems 20,348-356.

Sheaves M, Johnston R, Connolly R (2010) Temporal dynamics of fish assemblages of 11 tropical estuaries. Marine Ecology Progress Series 410, 143-157.

Simon TP (2000) The use of biological criteria as a tool for water resource management. Environmental Science and Policy 3(s1), 43-49.

Smith MKS, King CM, Sauer WHH, Cowley PD (2007) Development of fishery indicators for local management initiatives - a case study for Plettenberg Bay, South Africa. African Journal of Marine Science 29,511-525.

Steinitz O, Heller J, Tsoar A, Rotem D, Kadmon R (2005) Predicting regional patterns of similarity in species composition for conservation planning. Conservation Biology 19,1978-1988.

Ward T, Butler E, Hill B (1998) Environmental Indicators for National State of the Environment Reporting, Commonwealth of Australia, Canberra.

Whitfield AK, Elliott M (2002) Fishes as indicators of environmental and ecological changes within estuaries: a review of progress and some suggestions for the future. Journal of Fish Biology 61(sA),229-250. 


\section{Figure captions}

Figure 1: Location map showing location and coastline spanned by each of the studies from which data were obtained.

Figure 2: Relationships between mean catch per unit effort (CPUE), mean probability of encounter (PoE) and species richness $(\mathrm{S})$ versus naturalness.

Figure 3: Relationships between probability of encounter (PoE) and catch per unit effort (CPUE) for Leiognathus equulus (upper) and Penaeus merguiensis (lower). Both regressions significant $\mathrm{p}<0.01$.

Figure 4: Species richness (S) versus catch per unit effort based eveness ( $\left.\mathrm{J}_{\mathrm{CPUE}}\right)$ for Doughboy Creek and 'The Lakes' (diamonds = Curralea, triangles = Keyatta). Contours are Shannon-Weaver diversity $(\mathrm{H})$. Numbers in square brackets indicate trip numbers.

Figure 5: Species richness in seven estuaries with good temporal replication for the pre-wet season of 2007 and the post-wet, dry and pre-wet seasons of 2008.

Figure 6: Comparisons of equitability ( $\mathrm{J}$ ) based on (a) catch per unit effort ( $\mathrm{J}_{\mathrm{CPUE}}$ ) and (b) probability of encounter $\left(\mathrm{J}_{\mathrm{PoE}}\right)$ for 10 estuaries in the post-wet season.

Figure 7: Mean probability of encounter (PoE) for the five natural Study 2 estuaries and Keyatta Lake.

Figure 8: Mean probability of encounter (PoE), species richness (S) and equitability based on probability of encounter $\left(\mathrm{J}_{\mathrm{PoE}}\right)$ for the 9 estuaries from Study 3.

Figure 9: Mean probability of encounter (PoE), species richness (S) and equitability based on probability of encounter ( $\mathrm{J}_{\mathrm{PoE}}$ ) for the Study 2 estuaries for (a) one post-wet and (b) one dry season sample. 
Figure 1:

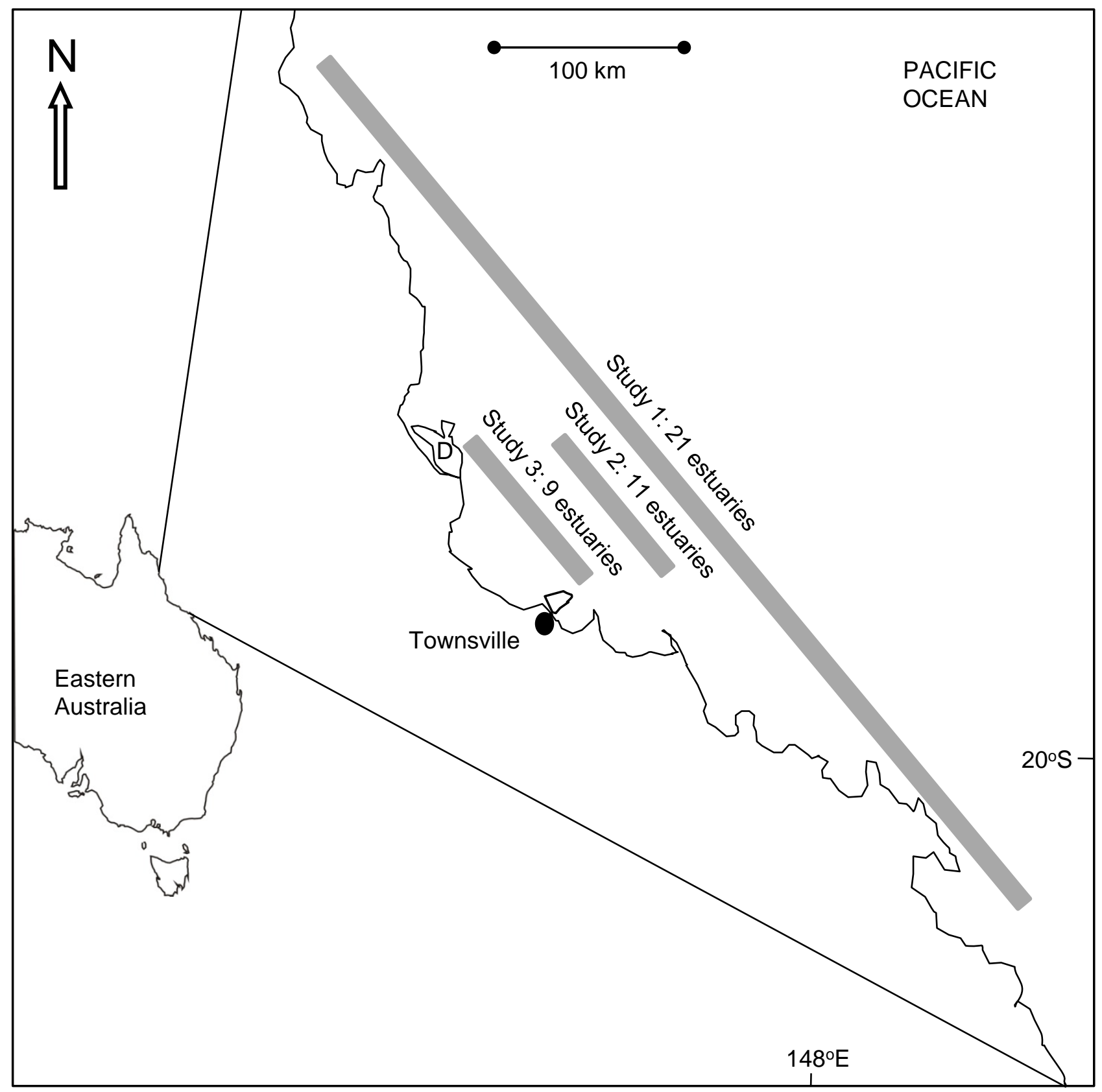


Figure 2:

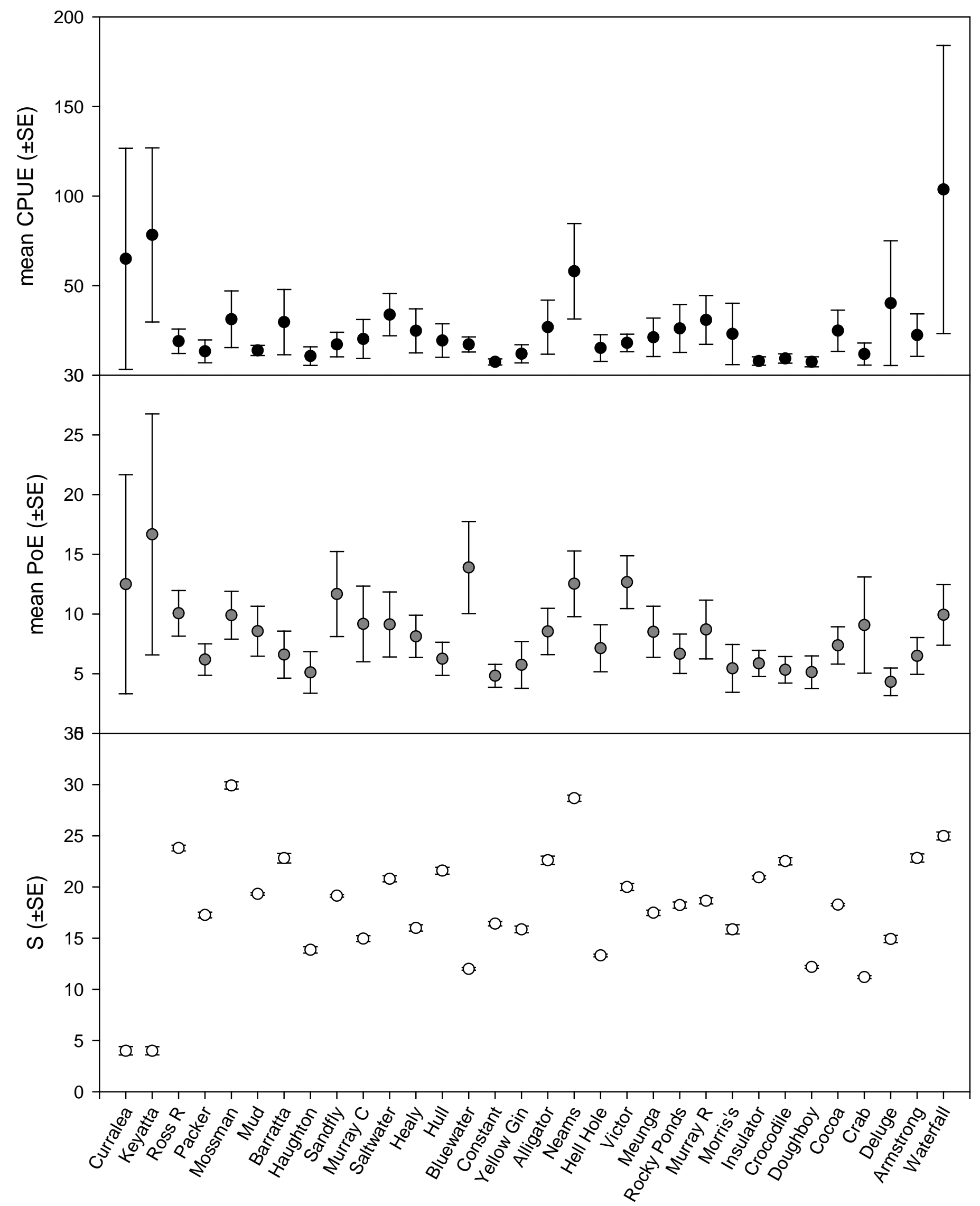


Figure 3

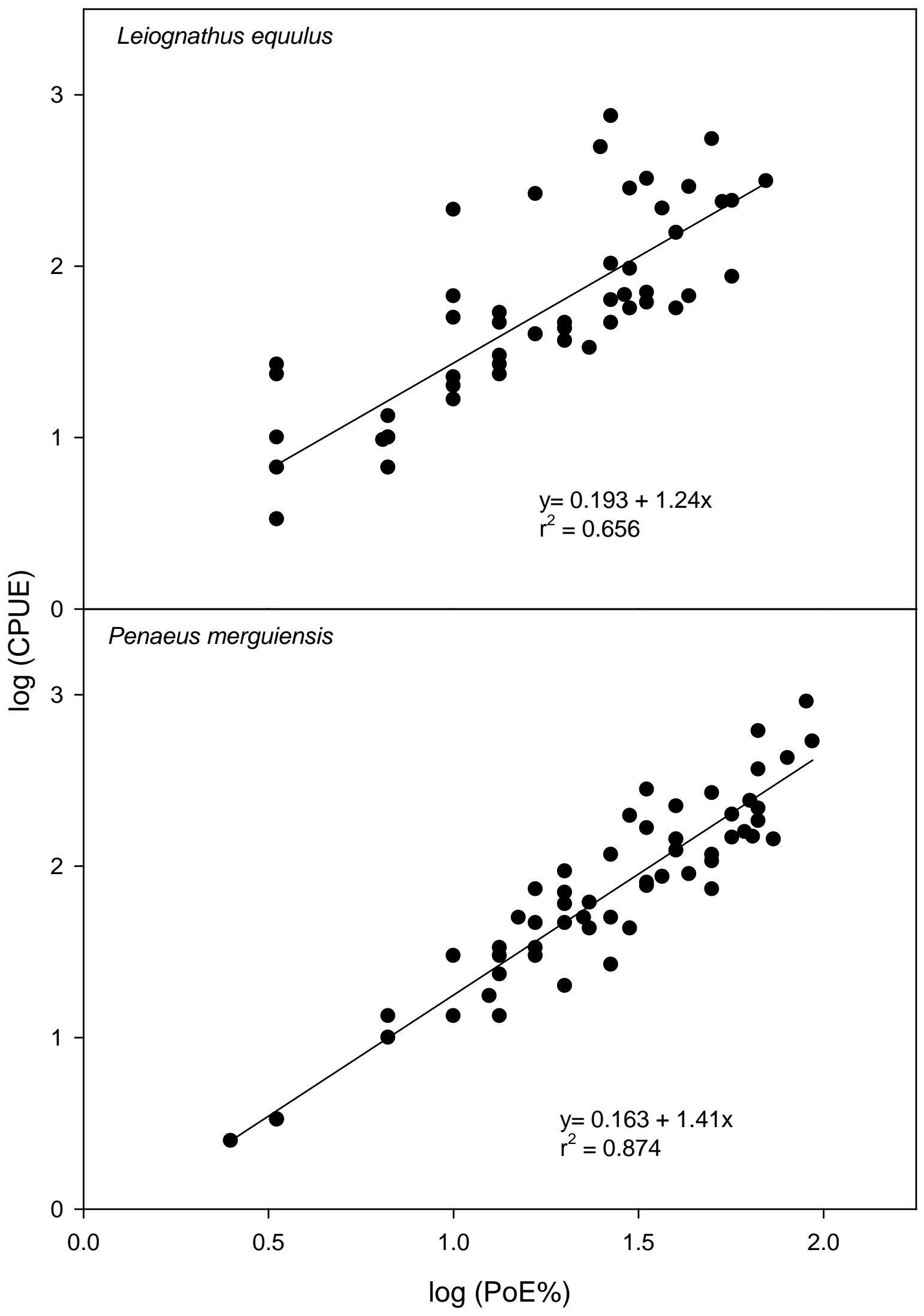


Figure 4:

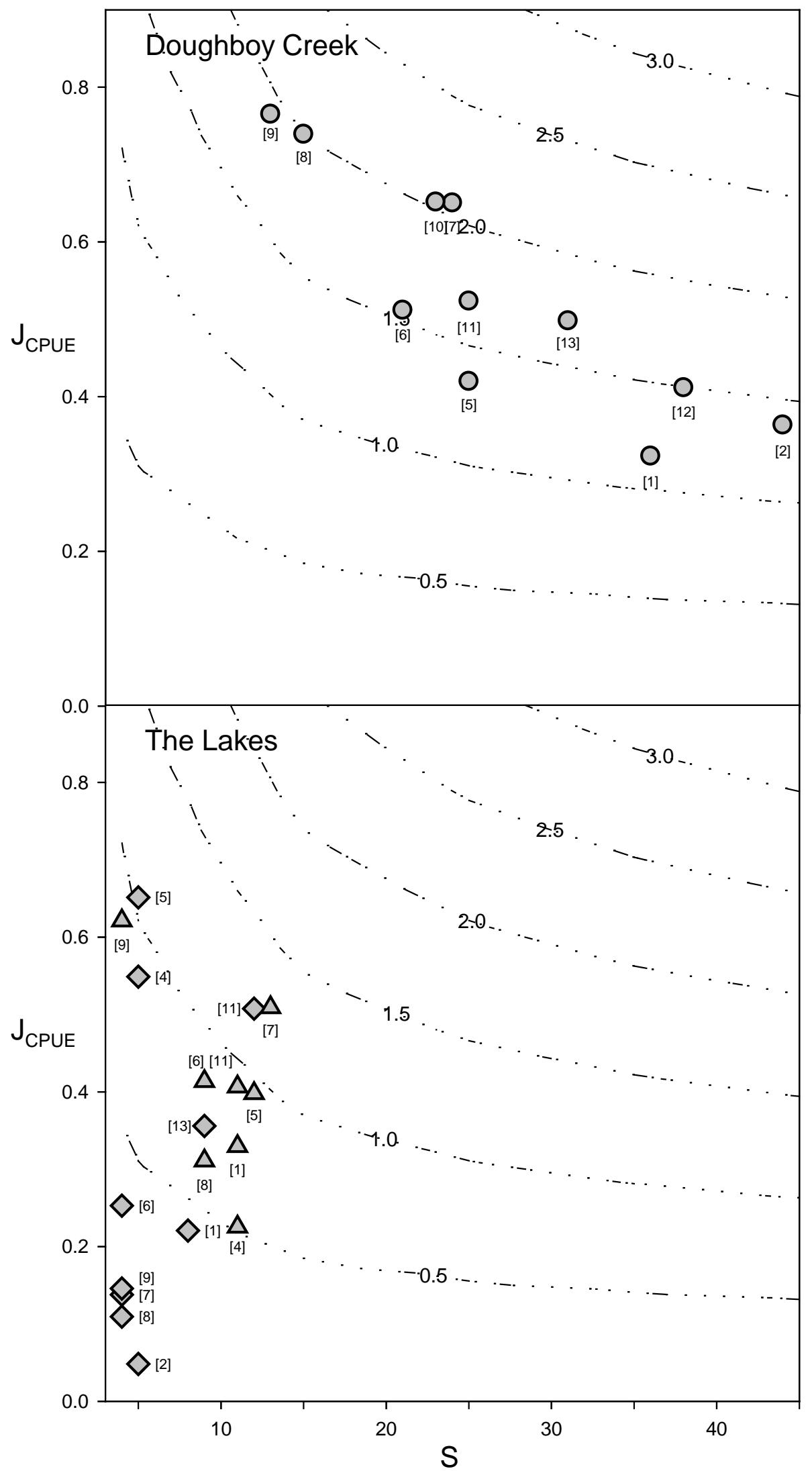


Figure 5:

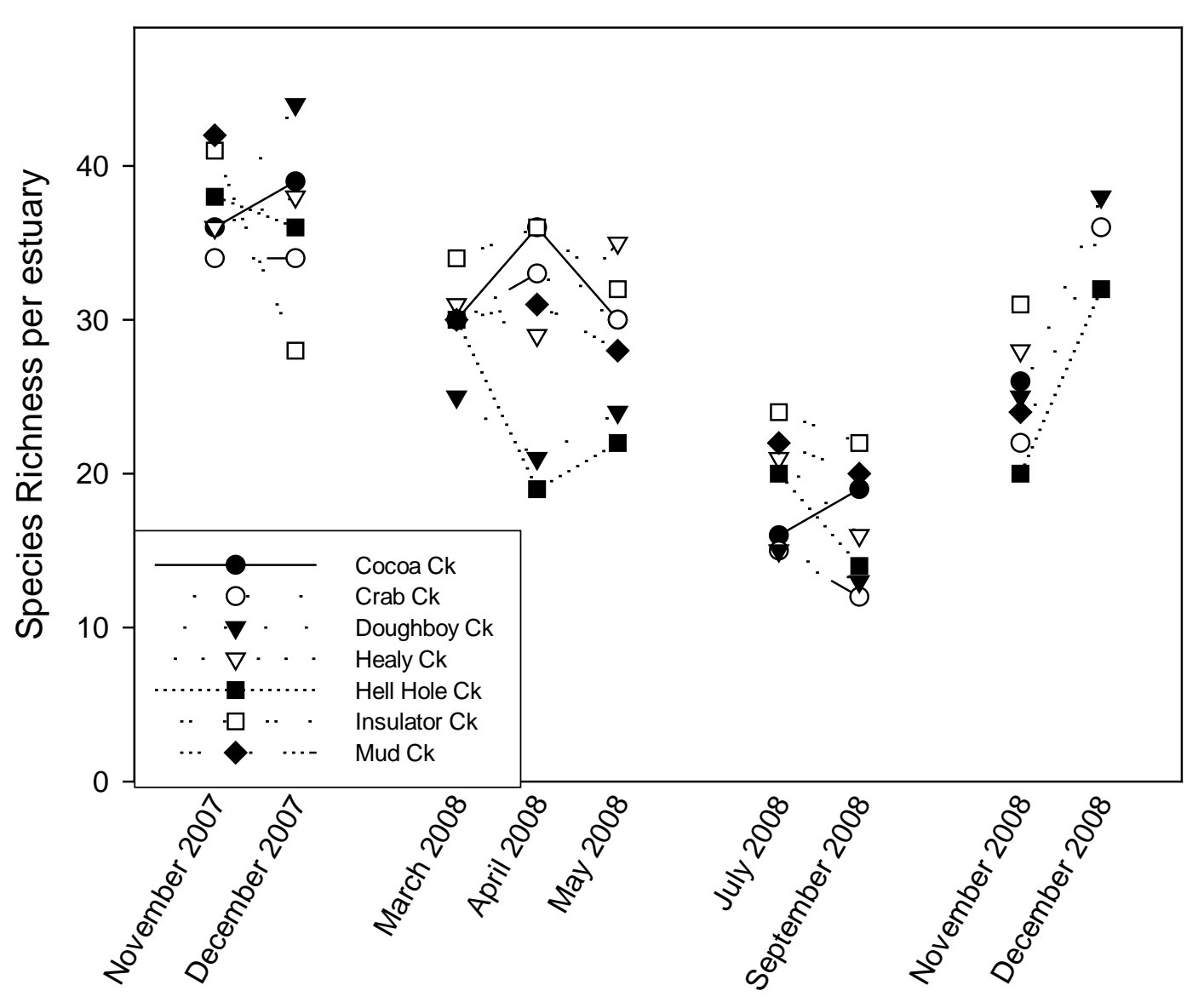


Figure 6

(a) Post-wet season $J_{\text {CPUE }}$

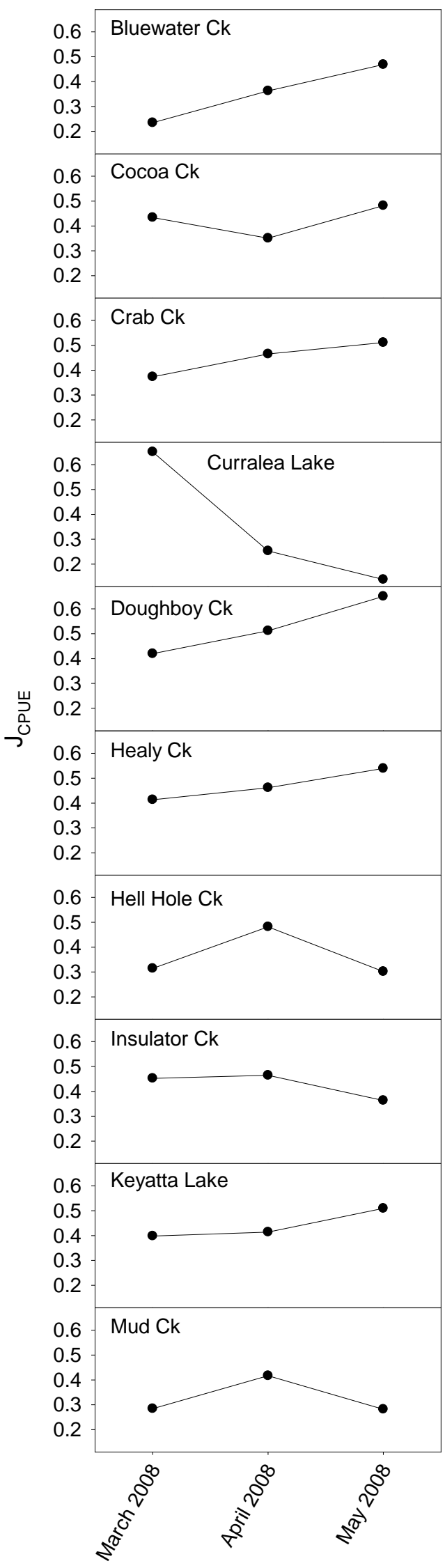

(b) Post-wet season $\mathrm{J}_{\mathrm{PoE}}$
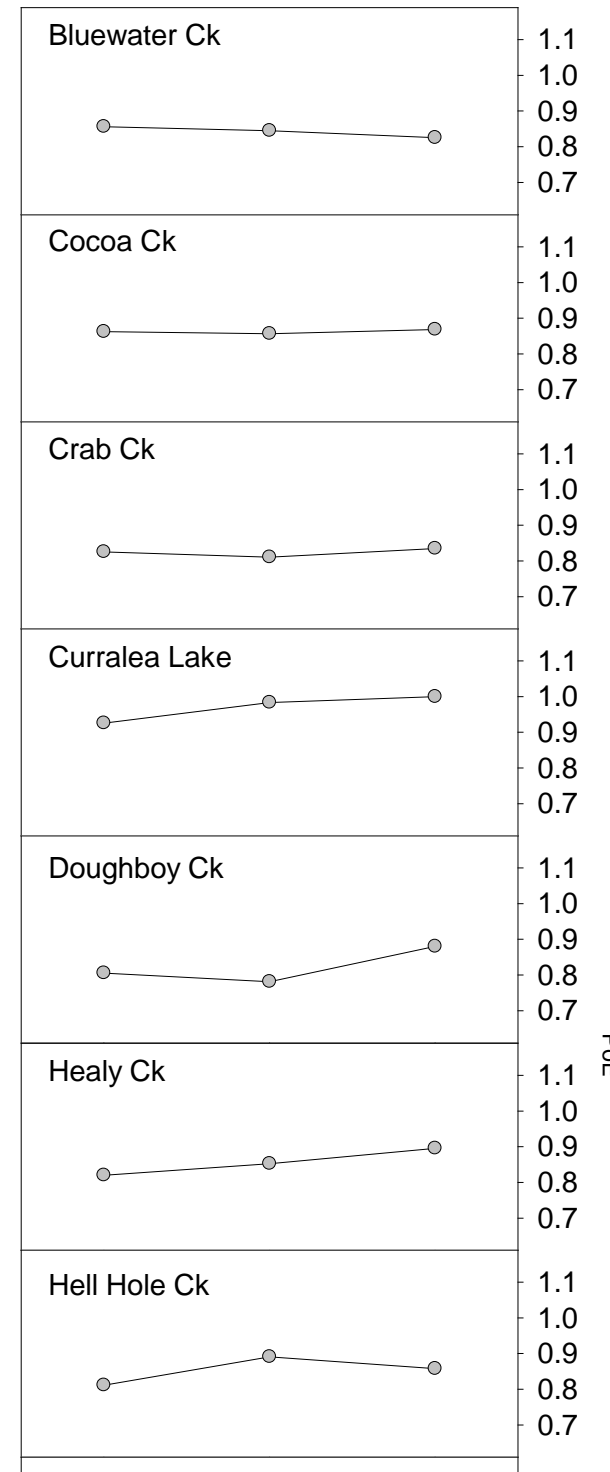

Insulator $\mathrm{Ck} \quad 1.1$

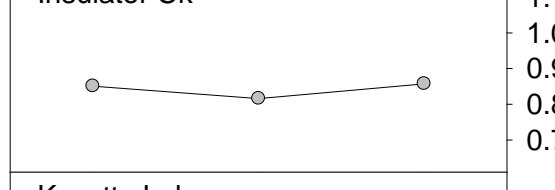

\begin{tabular}{|l|l}
\hline Keyatta Lake & 1.1
\end{tabular}

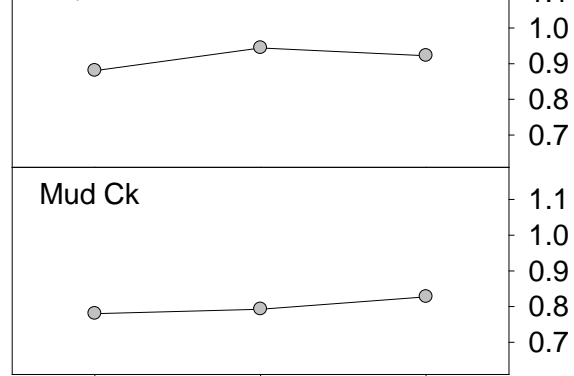


Figure 7:

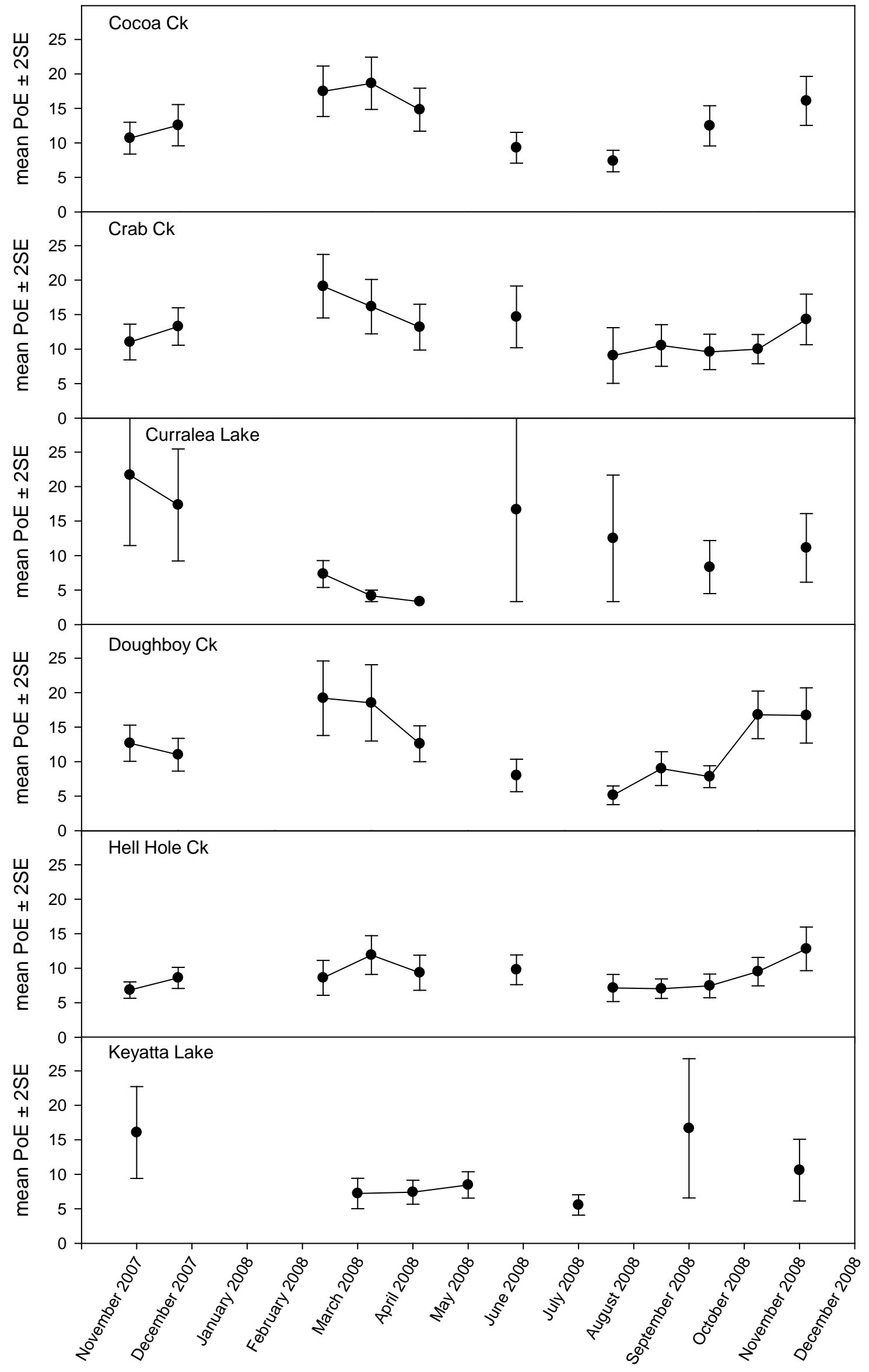


